\title{
NOVEMBRE-DÉCEMBRE 1981
}

63• ANNÉE - N• 732

\section{revue internationale de la croix-rouge}

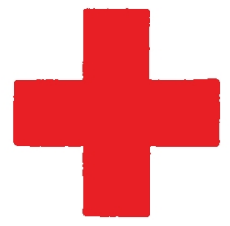

INTER ARMA CARITAS

GENEVE

COMITÉ INTERNATIONAL DE LA CROIX-ROUGE FONDÉ EN 1863 


\title{
COMITÉ INTERNATIONAL DE LA CROIX-ROUGE
}

MM. ALEXANDRE HAY, avocat, ancien directeur général de la Banque nationale suisse, président (membre depuis 1975)

HARALD HUUBER, docteur en droit, juge fédéral, vice-président (1969)

RICHARD PESTALOZZI, docteur en droit, vice-president (1977)

JEAN PICTET, docteur en droit, ancien vice-président du CICR (1967)

$M^{\text {me }}$ DENISE BINDSCHEDLER-ROBERT, docteur en droit, professeur à l'Institut universitaire de hautes études internationales, Genéve, juge à la Cour européenne des droits de l'homme (1967)

MM. MARCEL A. NAVILLE, licencié ès lettres, président du CICR de 1969 a 1973 (1967)

JACQUES F. DE ROUGEMONT, docteur en médecine (1967)

VICTOR H. UMBRICHT, docteur en droit, administrateur (1970)

GILBERT ETIENNE, professeur a l'Institut universitaire de hautes études internationales et à l'Institut d'études du développement, Genève (1973)

ULRICH MIDDENDORP, docteur en médecine, chef de la clinique chirurgicale de l'Hôpital cantonal, Winterthour (1973)

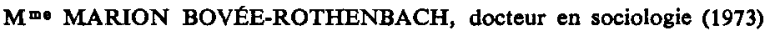

MM. HANS PETER TSCHUDI, docteur en droit, ancien conseiller fédéral (1973)

HENRY HUGUENIN, banquier (1974)

JAKOB BURCKHARDT, docteur en droit, ministre plénipotentiaire (1975)

THOMAS FLEINER, docteur en droit, professeur à l'Université de Fribourg (1975)

ATHOS GALLINO, docteur en médecine, maire de Bellinzone (1977)

ROBERT KOHLER, docteur ès sciences économiques (1977)

MAURICE AUBERT, docteur en droit, banquier (1979)

RUDOLF JACKLI, docteur ès sciences, géologue (1979)

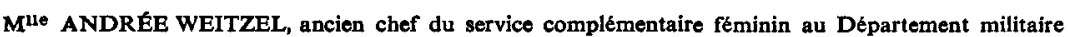
fédéral, vice-présidente de la Commission nationale suisse pour l'Unesco (1979)

MM. OLIVIER LONG, docteur en droit et docteur ès sciences politiques, ambassadeur, ancien directeur général du GATT (1980)

DIETRICH SCHINDLER, docteur en droit, professeur à l'Université de Zurích (1961-1973; 1980)

\section{CONSEIL EXÉCUTIF}

\author{
M. ALEXANDRE HAY, président \\ M. RICHARD PESTALOZZI \\ M. JAKOB BURCKHARDT \\ M. ATHOS GALLINO \\ M. RUDOLF JACKLI \\ M"• ANDREE WEITZEL
}




\section{REVUE INTERNATIONALE \\ DE LA CROIX-ROUGE}

ISSN 0035-3361

\section{SOMMAIRE}

NOVEMBRE-DÉCEMBRE $1981-\mathbf{N}^{\circ} 732$

COMITE INTERNATIONAL DE LA CROIX-ROUGE

FAITS ET DOCUMENTS
La XXIV ${ }^{e}$ Conférence internationale de la CroixRouge . . . . . . . . . . . . . . 319

Résolutions de la XXIV Conférence internationale de la Croix-Rouge. . . . . . . . . 326

Décisions de la XXIV Conférence internationale de la Croix-Rouge . . . . . . . . . . . . 354

Résolution du Conseil des Délégués . . . . . . 366 Décisions du Conseil des Délégués . . . . . 368

Ratification du Protocole I par le Viet Nam . . 370

Ratification des Protocoles par la Norvège . . . 370

Reconnaissance par le CICR de deux nouvelles Sociétés nationales . . . . . . . . . . . . 371

Activités extérieures:

Afrique - Amérique latine - Asie - Moyen-

Orient . . . . . . . . . . . . . 372

Lettre du CICR à l'ONU sur une enquête concernant l'utilisation alléguée d'armes chimiques . 386

Table des matières de l'année 1981. . . . . . . 391 
La Revue internationale de la Croix-Rouge est publiée par le Comité international de la Croix-Rouge depuis 1869.

Organe officiel du CICR,

publication spécialisée dans le droit international humanitaire, chronique des activités internationales de la Croix-Rouge,

la Revue internationale maintient un courant d'informations et constitue le lien nécessaire entre les membres de la Croix-Rouge internationale.

La Revue internationale de la Croix-Rouge paraît, une fois tous les deux mois, en trois éditions principales:

en français: Revue INTERNATIONALE DE LA CROIX-Rouge

en anglais: International ReVIEW OF THE Red Cross (depuis 1961)

en espagnol: Revista INTERnacional de LA CRUZ Roja (depuis 1976)

Elle publie également, en allemand, un cahier d'Extraits des textes parus dans les éditions principales.

RÉDAction: Michel Testuz

AdResse: $\quad$ Revue internationale de la Croix-Rouge

17, avenue de la Paix

CH - 1211 - Genève, Suisse

A bonnements: un an 30 francs suisses; le numéro 5 francs.

Extraits en allemand: un an 10 francs; le numéro 2 francs.

Compte de chèques postaux: $12-1767$ Genève

Compte bancaire: 129.986 Société de Banque Suisse, Genève

Seuls les textes signés par le Comité international de la Croix-Rouge engagent la responsabilité de celui-ci. 